\title{
Fontes e formas de aplicação da adubação fosfatada na cultura do girassol
}

\author{
Franciele Caroline de Assis VALADÃO ${ }^{1}$, Daniel Dias VALADÃO JÚNIOR ${ }^{1 *}$, Daniela Alves de SOUZA, \\ Max Sueliym Barrios RODRIGUES1, Leonardo Durval Duarte GUIMARÃES ${ }^{1}$
}

\author{
${ }^{1}$ Instituto Federal de Educação, Ciência e Tecnologia de Mato Grosso, Campo Novo do Parecis, Mato Grosso, Brasil. \\ (Orcid: 0000-0002-2046-3606; *; 0000-0002-9909-6959; 0000-0003-3650-0851; 0000-0003-0072-5856) \\ *E-mail: daniel.valadao@cnp.ifmt.edu.br (Orcid: 0000-0001-6395-9778)
}

Recebido em 16/04/2020; Aceito em 22/09/2020; Publicado em 05/10/2020.

\begin{abstract}
RESUMO: Os solos sob Cerrado são naturalmente pobres em fósforo, sendo imprescindível a sua adição aos sistemas agrícolas. No entanto, a fonte utilizada e a forma de aplicação podem afetar o resultado. Assim, objetivou-se nesse trabalho, avaliar as características vegetativas e produtivas do girassol em função do manejo da adubação fosfatada, utilizando diferentes fontes e formas de aplicação. Para isso, foram realizados dois experimentos, sendo um em Latossolo Vermelho-Amarelo distrófico de textura média e outro em Latossolo Vermelho distrófico de textura argilosa, sob delineamento em blocos casualizados em esquema fatorial $3 \times 4+1$ com quatro repetições. O primeiro fator refere-se a três fontes de $\mathrm{P}$, sendo uma fonte mineral (monoamônio fosfatado - MAP- 48\% de $\mathrm{P}_{2} \mathrm{O}_{5}$; $11 \%$ de $\mathrm{N})$, outra representada pelo $\mathrm{MAP}+$ substância húmica líquida $\left(0 \%\right.$ de $\mathrm{P}_{2} \mathrm{O}_{5} ; 2 \%$ de $\left.\mathrm{N}\right)$ e uma fonte organomineral granulado com substâncias húmicas $\left(26 \%\right.$ de $\mathrm{P}_{2} \mathrm{O}_{5} ; 5 \%$ de N). O segundo fator trata-se de quatro formas de aplicação do adubo sendo 100, 67,33 e $0 \%$ aplicado a lanço e o restante aplicado no sulco de semeadura. O tratamento adicional foi a não aplicação de P e substâncias húmicas. A fonte e a forma de aplicação do adubo fosfatado afetam a cultura do girassol. A produtividade de aquênios foi afetada pelos fatores testados, havendo interação significativa em ambos os solos. Para o Latossolo Vermelho-Amarelo o adubo MAP isolado pode ser aplicado 100\% a lanço sem redução de produtividade e quando em conjunto com substâncias húmicas, no mínimo $33 \%$ da dose deve que ser aplicada no sulco de semeadura. No Latossolo Vermelho tanto o MAP quanto o adubo organomineral tem que ser aplicado no mínimo $67 \%$ da dose no sulco de semeadura e quando for acrescido substâncias húmicas ao MAP, apenas $33 \%$ são necessários ser aplicado no sulco de semeadura.
\end{abstract}

Palavras-chave: fósforo; adubação organomineral; adubação a lanço; Hellianthus annus, teor de P.

\section{Sources and ways of application of phosphate fertilization in the sunflower culture}

\begin{abstract}
Soils under Cerrado are naturally low in phosphorus, and their addition to agricultural systems is essential. However, the source used and the form of application can affect the result. Thus, the objective of this work was to evaluate the vegetative and productive characteristics of the sunflower according to the management of phosphate fertilization, using different sources and forms of application. For this, two experiments were carried out, one in a Latossolo Vermelho-Amarelo distrófico with medium texture and the other in a Latossolo Vermelho Distrófico with clay texture, under a randomized block design in a $3 \times 4+1$ factorial scheme with four replications. The first factor refers to three sources of $\mathrm{P}$, one mineral source (phosphate monoammonium - MAP- 48\% P2O5; 11\% N), another represented by MAP + liquid humic substance $(0 \% \mathrm{P} 2 \mathrm{O} 5 ; 2 \% \mathrm{~N})$ and a granulated organomineral source with humic substances $(26 \%$ P2O5; 5\% $\mathrm{N})$. The second factor is four ways of applying the fertilizer, 100, 67, 33 and $0 \%$ applied to haul and the rest applied to the seeding furrow. The additional treatment was the non-application of $\mathrm{P}$ and humic substances. The source and form of application of the phosphate fertilizer affect the sunflower crop. The achenes productivity was affected by the tested factors, with significant interaction in both soils. For the Latossolo Vermelho-Amarelo, the isolated MAP fertilizer can be applied $100 \%$ by haul without reducing productivity and when in conjunction with humic substances, at least $33 \%$ of the dose must be applied in the seeding furrow. In the Latossolo Vermelho both MAP and organomineral fertilizer must be applied at least 67\% of the dose in the sowing furrow and when humic substances are added to the MAP, only $33 \%$ are necessary to be applied in the seeding furrow.

Keywords: phosphorus; organomineral fertilization; haul fertilization; Hellianthus annus; P content.
\end{abstract}

\section{INTRODUÇÃO}

O fósforo (P) é o segundo elemento mais exportado nos grãos do girassol, sendo que para cada mil quilogramas de grãos produzidos, a cultura extrai cerca de $24 \mathrm{~kg}$ de $\mathrm{P}$ correspondente a $55 \mathrm{~kg}$ de $\mathrm{P}_{2} \mathrm{O}_{5}$ (ZABIOLE et al., 2010). Assim, para se atingir alta produtividade é necessário que todo o $\mathrm{P}$ absorvido durante o ciclo da cultura seja reposto e esteja facilmente disponível no próximo cultivo, evitando que haja deficiências durante o novo ciclo. Neste aspecto, fatores como o manejo e fonte de fósforo podem influenciar a disponibilidade do nutriente para a cultura. 
Visando agilidade nas operações de cultivo, tem sido prática entre os agricultores a adoção da adubação fosfatada a lanço sem incorporação. Para solos com alta disponibilidade de $\mathrm{P}$ e/ou doses maiores que $100 \mathrm{~kg} \mathrm{ha}^{-1}$ de $\mathrm{P}_{2} \mathrm{O}_{5}$ a adubação a lanço pode ser adotada (SOUSA; LOBATO, 2004). Porém, devido à alta afinidade do $\mathrm{P}$ com os óxidos de $\mathrm{Fe}$ e $\mathrm{Al}$ presentes em abundância nos solos tropicais, a adubação a lanço pode aumentar a retenção do elemento na fase sólida e/ou ainda aumentar o gradiente de fertilidade, concentrando o nutriente na camada superficial do solo (SANTOS et al., 2008).

A maior concentração do $\mathrm{P}$ na superfície do solo pode reduzir o crescimento radicular em camadas mais profundas (VALADÃO et al., 2015). Esse fato tem especial importância para culturas cultivadas em segunda safra, tal como o girassol, que estão susceptíveis ao déficit hídrico no período reprodutivo. Além disso, a resposta do girassol a dose utilizada pode variar em razão do tipo e das características do solo presente (ELTZ et al. 2008), e em deficiência de P, a área foliar do girassol pode ser afetada comprometendo a capacidade fotossintética, retardando a floração e reduzindo a produção de aquênios (SANTOS et al., 2015).

Por outro lado, o tipo do adubo fosfatado também pode influenciar na disponibilidade do nutriente e consequentemente, no seu manejo. Alguns resultados de pesquisa indicam que a utilização de adubos fosfatados, juntamente com substâncias húmicas reduzem a sorção de $\mathrm{P}$ na fase sólida do solo aumentando a disponibilidade em solução (ANDRADE et al., 2003; FONTANA et al., 2008).

Os ácidos fúlvicos e húmicos, que são ácidos orgânicos de baixa massa molecular dominantes na constituição das substâncias húmicas, possuem cargas dependentes do $\mathrm{pH}$ da solução e em pH superior a 3,5 (valor de ponto de carga zero) predominam cargas negativas, graças à dissociação do $\mathrm{H}^{+} \mathrm{e}$ formação de água (PAVINATO; ROSOLEM, 2008). Com isso, pode ocorrer competição entre estes ácidos orgânicos e os nutrientes aniônicos pelos sítios de adsorção do solo, além disso, podem formar complexos organometálicos estáveis com Fe e $\mathrm{Al}$, que são os principais agentes ligantes ao $\mathrm{P}$, numa larga amplitude de $\mathrm{pH}$ do solo ( $\mathrm{pH} 4,0-7,0$ ) (ANDRADE et al., 2003). Por conta disto, o adubo fosfatado contendo substâncias húmicas pode ser mais eficiente na disponibilidade de $\mathrm{P}$ para as plantas, o que poderá indicar necessidade de menor dose de aplicação para atingir maiores produtividades.

As pesquisas divulgadas com fertilizantes organominerais apresentam resultados divergentes sobre a eficiência desses produtos. Ao compararem adubo organomineral com mineral, Rodrigues et al. (2012) e Lana et al. (2014) não verificaram diferenças na produtividade do milho. Porém, Dania et al. (2012), em solo degradado sob erosão superficial, obtiveram maiores produtividade de milho com a utilização de fertilizante organomineral. Santos et al. (2008) encontraram respostas positivas do girassol a incrementos de doses de adubo organomineral.

$\mathrm{Na}$ cultura do girassol são poucas as pesquisas que comparam a eficiência dos adubos organominerais, bem como, a influência do manejo da adubação fosfatada sobre seus componentes produtivos em diferentes solos e em condições de solos bastante intemperizados, geralmente, pobres em matéria orgânica. Diante do exposto, as hipóteses desse trabalho são: 1) a fonte de adubo fosfatado afeta a sua eficiência; 2) a forma de aplicação do adubo fosfatado não pode ser igual para todas as fontes; 3) o solo interfere na resposta da cultura ao se variar a fonte e a forma de aplicação; 4) as substâncias húmicas podem ser uma alternativa para melhorar a eficiência do adubo fosfatado em solos de cerrado. Assim, objetivou-se nesse trabalho, avaliar as características vegetativas e produtivas do girassol em função do manejo da adubação fosfatada, utilizando diferentes fontes e formas de aplicação.

\section{MATERIAL E MÉTODOS}

Foram realizados dois experimentos em Campo Novo do Parecis-MT no período de março a julho de 2014 com a cultura do girassol, sendo um na fazenda Campo Belo localizada a $13^{\circ} 55^{\prime} 07.8^{\prime \prime}$ de latitude Sul; 57 58'37.8" de longitude Oeste e 625 $\mathrm{m}$ de altitude, com Latossolo Vermelho-Amarelo Distrófico típico de textura média (LVA) (EMBRAPA, 2018), outro na área experimental do Instituto Federal de Educação, Ciência e Tecnologia de Mato Grosso (IFMT), localizada pelas coordenadas geográficas $13^{\circ} 40^{\prime} 31^{\prime \prime}$ de latitude Sul; $57^{\circ} 53^{\prime} 31^{\prime \prime}$ de longitude Oeste e $564 \mathrm{~m}$ de altitude em Latossolo Vermelho Distrófico típico de textura argilosa (LVE) (EMBRAPA, 2018).

Para caracterização química e da textura do solo de cada área foi feita a análise em amostras retiradas na camada de 0,0 a $0,2 \mathrm{~m}$ sendo os resultados apresentado na Tabela 1.

Tabela 1. Caracterização do Latossolo Vermelho-Amarelo (LVA) textura média (Fazenda Campo Belo) e do Latossolo Vermelho (LVE) textura argilosa (IFMT), Campo Novo do Parecis-MT.

Table 1. Characterization of Latossolo Vermelho-Amarelo (LVA), medium texture (Fazenda Campo Belo) and Latossolo Vermelho (LVE), clay texture (IFMT), Campo Novo do Parecis-MT.

\begin{tabular}{|c|c|c|}
\hline Atributos* & LVA & LVE \\
\hline pH em água & 5,3 & 5,9 \\
\hline $\mathrm{pH} \mathrm{em} \mathrm{CaCl}_{2}$ & 4,5 & 5,2 \\
\hline $\mathrm{P}\left(\mathrm{mg} \mathrm{dm}^{-3}\right)$ & 17,7 & 4,5 \\
\hline $\mathrm{K}\left(\mathrm{mg} \mathrm{dm}^{-3}\right.$ & 22 & 88 \\
\hline $\mathrm{Ca}\left(\mathrm{cmol}_{\mathrm{c}} \mathrm{dm}^{-3}\right)$ & 0,9 & 2,3 \\
\hline $\mathrm{Mg}\left(\mathrm{cmol}_{\mathrm{c}} \mathrm{dm}^{-3}\right)$ & 0,4 & 0,9 \\
\hline $\mathrm{H}\left(\mathrm{cmol}_{\mathrm{c}} \mathrm{dm}^{-3}\right)$ & 2,6 & 3,7 \\
\hline $\mathrm{Al}\left(\mathrm{cmol}_{\mathrm{c}} \mathrm{dm}^{-3}\right)$ & 0,3 & 0 \\
\hline $\mathrm{B}\left(\mathrm{mg} \mathrm{dm}^{-3}\right)$ & 0,36 & 0,39 \\
\hline Soma de Bases $\left(\mathrm{cmol}_{\mathrm{c}} \mathrm{dm}^{-3}\right)$ & 1,35 & 3,42 \\
\hline CTC total $\left(\mathrm{cmol}_{\mathrm{c}} \mathrm{dm}^{-3}\right)$ & 4,25 & 7,12 \\
\hline Saturação por Bases (\%) & 31,76 & 48,03 \\
\hline Matéria Orgânica $\left(\mathrm{g} \mathrm{dm}^{-3}\right)$ & 11,8 & 27,1 \\
\hline Argila $\left(\mathrm{g} \mathrm{kg}^{-1}\right)$ & 178 & 588 \\
\hline Silte $\left(\mathrm{g} \mathrm{kg}^{-1}\right)$ & 49 & 156 \\
\hline Areia $\left(\mathrm{g} \mathrm{kg}^{-1}\right)$ & 773 & 256 \\
\hline
\end{tabular}

*Conforme metodologia da EMBRAPA (1997). $\mathrm{pH}$ em $\mathrm{H}_{2} \mathrm{O}$ e $\mathrm{CaCl}_{2}(0,01$ mol L-1 : relação 1:2,5; P e K: extrator Mehlich-1; $\mathrm{Ca}^{2+}, \mathrm{Mg}^{2+}, \mathrm{Al}^{3+}$ : $\mathrm{KCl} 1$ mol L-1. $\mathrm{H}^{+}+\mathrm{Al}^{3+}$ : método $\mathrm{Ca}(\mathrm{OAc})_{2} 0,5 \mathrm{~mol} \mathrm{~L}^{-1}, \mathrm{pH} 7$; matéria orgânica: Walkley Black

De acordo com os preceitos de Köppen, referidos por Vianello; Alves (2004), o clima da região é o tropical quente e úmido $\left(\mathrm{A}_{\mathrm{w}}\right)$ com temperatura média de $23,7^{\circ} \mathrm{C}$. A precipitação pluviométrica média nas áreas, durante o período de março a julho, foi respectivamente de $760 \mathrm{~mm}$ na área de Latossolo Vermelho-Amarelo e de $730 \mathrm{~mm}$ na área de Latossolo Vermelho.

A área do Latossolo Vermelho-Amarelo foi cultivada com cana-de-açúcar até a safra 2012/2013, após a colheita da cana-deaçúcar foi cultivada a soja no final de outubro, sendo sua adubação no sulco de semeadura. A área do Latossolo Vermelho foi mantida sobre vegetação espontânea até a safra 2009/2010 quando a área foi gradeada e calcáriada com $2 \mathrm{Mg} \mathrm{ha}{ }^{-1}$ utilizando calcário dolomítico (PRNT $=85 \%$ ) sendo introduzida a cultura da soja na primeira safra e milho na segunda. A adubação das duas culturas seguia recomendação de Sousa; Lobato (2004) sempre no sulco de 
semeadura. Os experimentos foram implantados sobre os resíduos de soja cultivada em outubro de 2013 e colhida em fevereiro de 2014.

O delineamento experimental adotado em cada área foi o de blocos completos casualizados com quatro repetições seguindo um fatorial $3 \times 4+1$. O primeiro fator refere-se a três fontes de fósforo, sendo uma fonte mineral representada pelo monoamônio fosfato - MAP ( $48 \%$ de $\mathrm{P}_{2} \mathrm{O}_{5} ; 11 \%$ de $\left.\mathrm{N}\right)$, outra representada pela aplicação do MAP juntamente com a substância húmica líquida $\left(0 \%\right.$ de $\mathrm{P}_{2} \mathrm{O}_{5} ; 2 \%$ de $\left.\mathrm{N}\right)$ e uma fonte organomineral granulado com substâncias húmicas $(26 \%$ de $\mathrm{P}_{2} \mathrm{O}_{5} ; 5 \%$ de N). O segundo fator trata-se de quatro formas de aplicação da adubação fosfatada, sendo 100, 67, 33 e $0 \%$ da dose de $80 \mathrm{~kg} \mathrm{ha}^{-1}$ de $\mathrm{P}_{2} \mathrm{O}_{5}$ aplicado a lanço e o restante aplicado no sulco de semeadura. O tratamento adicional foi feito sem aplicação de fósforo e substâncias húmicas.

O produto líquido utilizado como fonte de substâncias húmicas foi obtido por meio de extração de turfas estabilizadas, ricas em carbono orgânico, cuja porcentagem de ácidos fúlvicos e húmicos é de $13 \%$, utilizando a dose de $150 \mathrm{~L} \mathrm{ha}^{-1}$, sendo aplicada no sulco de semeadura. A outra fonte de substâncias húmicas utilizada no experimento foi o fertilizante organomineral sólido e peletizado com a formulação 04-26-00. A caracterização química dos adubos utilizados nesse experimento encontra-se na Tabela 2. Em março logo após a colheita da soja, foi realizado o preparo das áreas para a instalação do experimento mediante dessecação das plantas daninhas utilizando herbicida de princípio ativo glifosato na dose de $2,0 \mathrm{~L} \mathrm{ha}^{-1}$. Na calda do dessecante, foi adicionado ácido bórico na dose de $2,0 \mathrm{~kg} \mathrm{ha}^{-1}$ de boro.

Tabela 2. Caracterização dos adubos utilizados nos tratamentos, Campo Novo do Parecis-MT.

Table 2. Characterization of fertilizers used in treatments, Campo Novo do Parecis-MT.

\begin{tabular}{|c|c|c|c|}
\hline \multirow{2}{*}{ Atributo analisado } & SHS $^{1}$ & $\mathrm{MAP}^{2}$ & $\mathrm{ORG}^{3}$ \\
\hline & \multicolumn{3}{|c|}{ Teores totais em $\%$} \\
\hline Nitrogênio & 1,7 & 11,15 & 5,02 \\
\hline Potássio & 1,53 & 0,05 & 0,12 \\
\hline Fósforo & 0,02 & 48,47 & 26,13 \\
\hline Carbono orgânico & 3,5 & 0 & 8,2 \\
\hline Extrato húmico total & 10,8 & 0 & 12,13 \\
\hline Ácidos Húmicos & 5,5 & 0 & 6 \\
\hline Ácidos Fúlvicos & 5,3 & 0 & 6,13 \\
\hline
\end{tabular}

Metodologia conforme Instrução Normativa n. 28 de 27/07/2007 do Ministério da Agricultura Pecuária e Abastecimento - MAPA; ${ }^{1} \mathrm{SHS}$ Substâncias húmicas; ${ }^{2} \mathrm{MAP}$ : Monoamônio fosfatado; ${ }^{3} \mathrm{ORG}$ : Organomineral.

A unidade experimental foi composta de uma parcela de seis linhas com quatro metros de comprimento, espaçadas de 0,45 $\mathrm{m}$, perfazendo área de $10,8 \mathrm{~m}^{2}$. O híbrido de girassol utilizado foi Olyssun 3, com densidade de 2,7 sementes por metro linear com profundidade de semeadura de $0,03 \mathrm{~m}$ estimando-se população de 60.000 plantas ha-1.

A adubação e a semeadura ocorreram de forma manual, sendo a abertura dos sulcos feita de forma mecanizada utilizando uma semeadora equipada com discos. $\mathrm{Na}$ adubação de semeadura aplicou-se em todos os tratamentos como fonte de potássio o $\mathrm{KCl}\left(60 \%\right.$ de $\left.\mathrm{K}_{2} \mathrm{O}\right)$, na dose de $60 \mathrm{~kg} \mathrm{ha}^{-1}$. A diferença de nitrogênio fornecida pelas fontes de $\mathrm{P}$ foi fornecida na forma de ureia ( $45 \%$ de $\mathrm{N}$ ) aplicada conforme tratamento. Aos 25 e 45 dias após semeadura (DAS) foram realizadas as adubações de cobertura com ureia na dose de $50 \mathrm{~kg} \mathrm{ha}^{-1}$ de N. Aos 20 DAS foi feita a adubação com boro, $\left(\mathrm{H}_{3} \mathrm{BO}_{3} 17 \%\right)$, aplicado via foliar na dose de $2,0 \mathrm{~kg} \mathrm{ha}^{-1}$.
O monitoramento e o controle de plantas daninhas, insetospragas e doenças foram feitos semanalmente. Para as plantas daninhas o controle foi através da capina manual até o momento em que a cultura obteve domínio sobre as plantas invasoras, dispensando assim a capina. As pragas encontradas foram à vaquinha (Diabrotica speciosa), e a lagarta do girassol (Chlosyne lacinia saundersii). Sendo feito o controle aos 26 DAS e depois com intervalo de sete dias com o inseticida sistêmico, de contato e ingestão de princípio ativo Tiametoxan e o inseticida de contato e ingestão com princípio ativo de Flubendiamida nas doses de $0,30 \mathrm{~L} \mathrm{ha}^{-1}$ e $0,12 \mathrm{~L} \mathrm{ha}^{-1}$, respectivamente. A principal doença encontrada, foi a mancha de alternaria (Alternaria spp) fazendose o controle com duas aplicações do fungicida sistêmico com princípio ativo de Azoxistrobina e Ciproconazol na dose de 0,25 $\mathrm{L} \mathrm{ha}^{-1}$, na qual a primeira foi aos 26 DAS e a segunda aos 41 DAS.

As avaliações ocorreram nasfases de florescimento e colheita.

No florescimento: 1) altura de plantas: foram medidas quatro plantas por parcela, do solo até a inserção do capitulo utilizando-se de uma trena ( $\mathrm{m})$; 2) diâmetro da haste: das mesmas plantas em que se mediu a altura, foi medido a $0,05 \mathrm{~m}$ do solo o diâmetro da haste utilizando um paquímetro digital (mm); 3) massa seca de planta: foram coletadas duas plantas por parcela cortando as mesmas rente ao solo e levando-as a estufa de ventilação forçada a uma temperatura de $65^{\circ} \mathrm{C}$ até a obtenção de massa constante. Depois foi extrapolado para área, obtendo-se a massa seca por hectare $\left(\mathrm{kg} \mathrm{ha}^{-1}\right)$; 4) teor de P nas folhas: retirouse todas as folhas das plantas utilizadas na obtenção da massa, fez-se a moagem das mesmas e determinou-se o teor de $\mathrm{P}\left(\mathrm{g} \mathrm{kg}^{-}\right.$ 1) conforme EMBRAPA (2009).

Na colheita: 1) estande final de plantas: contou-se o número de plantas presentes em quatro metros lineares na região central de cada parcela e calculou-se a população de plantas no hectare (plantas ha-1);2) diâmetro do capítulo: foi medido o diâmetro do capítulo em todas as plantas da área útil (mm); 3) massa de 100 aquênios: determinou-se a massa, em duplicata, para 100 aquênios obtidos de maneira aleatória em cada parcela, padronizando para uma umidade de $11 \%(\mathrm{~g})$; 3) produtividade de aquênios: após a colheita manual de todas as plantas da área útil, fez-se a trilha mecânica, a limpeza e a determinação da massa e da umidade. Em seguida, foi padronizado para uma umidade de $11 \%$ e fez a projeção por hectare $\left(\mathrm{kg} \mathrm{ha}^{-1}\right)$.

Os resultados foram submetidos à análise de variância $\mathrm{e}$, quando F significativo $(\mathrm{p}<0,05)$, foi aplicado o teste de média Dunett $(p<0,05)$ para a interação significativa entre tratamento adicional e o fatorial e o teste de média Tukey $(\mathrm{p}<0,05)$ para os fatores fontes e formas de aplicação de fósforo respeitando as respectivas interações.

\section{RESULTADOS}

O ciclo do girassol foi de 110 dias e entre as características avaliadas apenas estande não foi influenciado pelos tratamentos com média geral de 58.945 plantas ha $^{-1}$ para o Latossolo Vermelho-Amarelo e 55.985 plantas $\mathrm{ha}^{-1}$ para o Latossolo Vermelho.

Para a altura de planta, diâmetro da haste e massa seca da planta não houve efeito da interação entre adubos e forma da adubação, nem dos fatores isolados. Entretanto, todos os tratamentos proporcionaram maior altura de planta e diâmetro da haste que o tratamento sem fósforo. Para massa seca, os adubos fornecidos 100\% a lanço e o MAP fornecido 67 e 33\% a lanço tiveram resultados semelhantes aos tratamentos sem fósforo. Houve 
interação entre os fatores para o teor de $\mathrm{P}$ foliar, diâmetro do capítulo, massa de cem aquênios, produtividade de aquênios.

Em relação ao teor de $\mathrm{P}$ na folha, houve diferença entre as formas de parcelamento da adubação, mas não houve diferença entre os adubos em cada forma de parcelamento. Para o MAP houve redução no teor de P foliar nas formas de 67 e 100\% da dose aplicada a lanço, para o MAP+SHS e o organomineral houve redução com $100 \%$ a lanço. Os três adubos quando aplicados $100 \%$ a lanço não diferiram do tratamento sem $\mathrm{P}$, os demais tratamentos com no mínimo 33\% da dose do adubo fosfatado aplicado no sulco de semeadura proporcionaram teores de $\mathrm{P}$ maiores que aquele sem adição de $\mathrm{P}$.

Tabela 3. Atributos produtivos do girassol em função dos adubos fosfatados da forma de aplicação em Latossolo Vermelho-Amarelo, Campo Novo do Parecis-MT.

Table 3. Productive attributes of sunflower as a function of phosphate fertilizers of the application form in Latosolo Vermelho-Amarelo, Campo Novo do Parecis-MT.

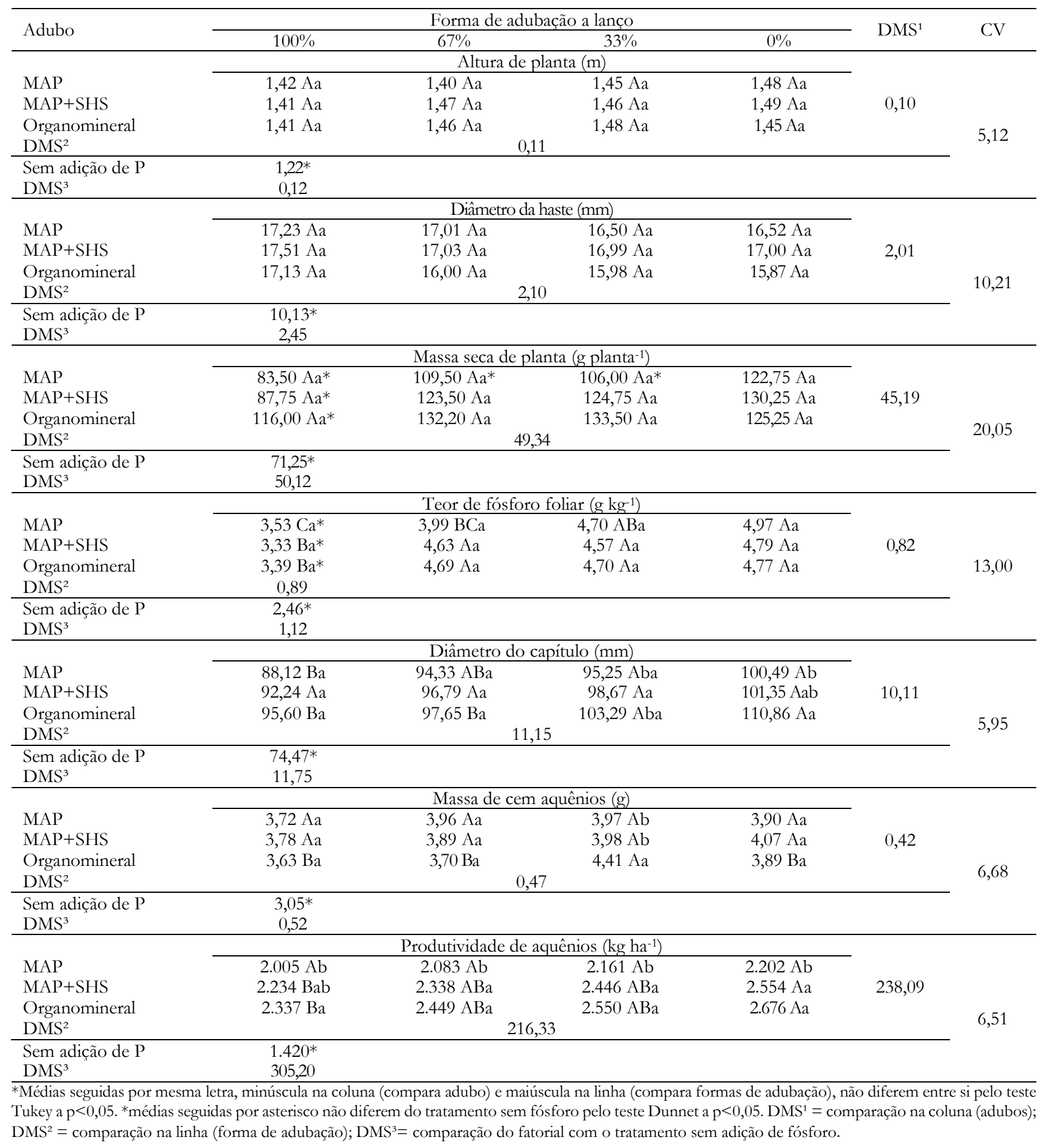

Os adubos MAP e organomineral quando aplicados 100 e 67\% a lanço reduziram o tamanho dos capítulos do girassol e para o $\mathrm{MAP}+\mathrm{SHS}$ não houve diferença entre as formas. Quando aplicados todo no sulco de semeadura, o adubo organomineral proporcionou maior diâmetro do capítulo. Todos os tratamentos proporcionaram maior tamanho de capítulo quando comparado 
com o tratamento sem fósforo.

No caso da massa de cem aquênios, observa-se que para MAP e MAP+SHS não houve diferença entre as formas de aplicação, no organomineral a maior massa de grãos foi obtida quando foi fornecida 33\% da dose aplicada a lanço. Nessa forma de aplicação o MAP e MAP+SHS proporcionaram menor massa de cem aquênios quando comparados com o organomineral. Todos os tratamentos resultaram em maior massa de aquênios quando comparados ao tratamento sem fósforo.

A produtividade de aquênios não foi afetada pela forma de aplicação quando se utilizou exclusivamente o MAP, porém, quando se utilizou os adubos contendo substâncias húmicas, $\mathrm{MAP}+\mathrm{SHS}$ e o organomineral, houve redução de produtividade conforme se aumentou a quantidade de adubo aplicada a lanço. Para esses adubos, houve redução de aproximadamente 13\% de produtividade no tratamento $100 \%$ a lanço comparado ao tratamento $0 \%$ a lanço.

Tabela 4. Atributos produtivos do girassol em função dos adubos fosfatados e forma de aplicação em Latossolo Vermelho, Campo Novo do Parecis-MT.

Table 4. Productive attributes of sunflower as a function of phosphate fertilizers of the application form in Latosolo Vermelho, Campo Novo do Parecis-MT.

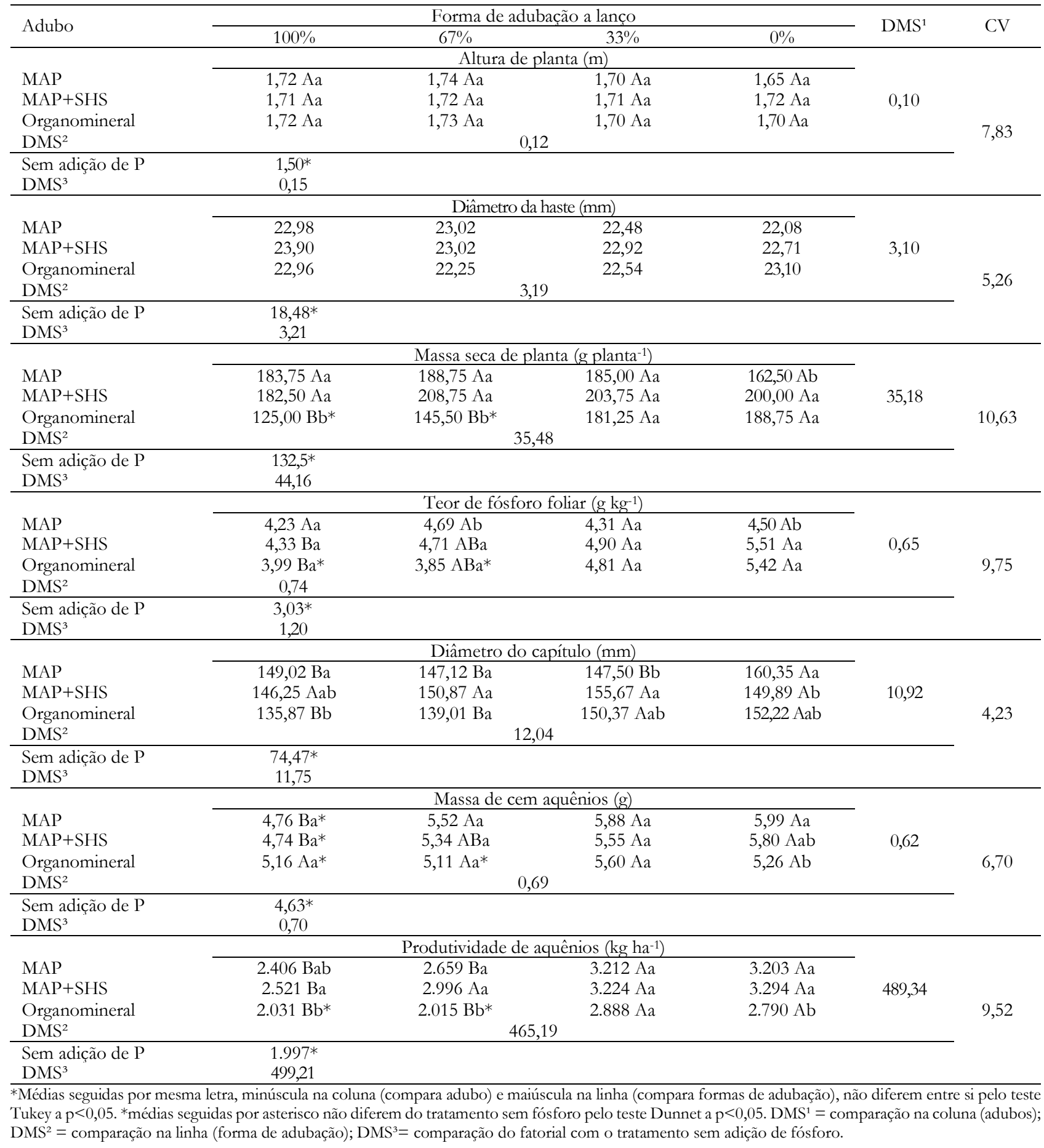


Não se observou interação entre adubos fosfatados e forma de adubação para altura e diâmetro da haste, sendo que todos os tratamentos proporcionaram maiores valores que o tratamento sem adição de fósforo.

A massa seca de planta, apresentou interação entre os fatores, sendo que não houve diferença entre as formas de adubação para os adubos MAP e MAP+SHS. Quando se utilizou o adubo organomineral com 100 e $67 \%$ da dose aplicada a lanço houve redução de 34 e $23 \%$ no acúmulo de massa seca quando comparado com toda a dose aplicada no sulco de semeadura, respectivamente. Esses mesmos tratamentos não diferiram do tratamento sem adição de fósforo. Quando a forma de aplicação do adubo fosfatado foi toda no sulco de semeadura, os adubos contendo substâncias húmicas (MAP+SHS e organomineral) proporcionaram maior massa seca de planta quando comparado ao MAP sem substâncias húmicas. Com o aumento da dose aplicada a lanço não houve diferença entre $\mathrm{MAP}$ e MAP+SHS e o organomineral proporcionou menor massa seca de planta.

$\mathrm{O}$ teor de $\mathrm{P}$ foliar foi afetado de maneira diferente entre as fontes. Para o MAP não houve diferença entre as formas de parcelamento, para o MAP+SHS e para o organomineral, houve redução dos teores de $\mathrm{P}$ na folha do girassol quando a adubação foi toda feita a lanço. $\mathrm{O}$ adubo organomineral aplicado $67 \mathrm{e}$ $100 \%$ a lanço proporcionaram teores de P semelhante aquele onde não foi fornecida adubação fosfatada.

O MAP quando fornecido a lanço e o organomineral em 100 e $67 \%$ da dose a lanço, reduziram o tamanho do capítulo, enquanto para o MAP+SHS não houve diferença entre as formas de aplicação. Todos os tratamentos proporcionaram maior tamanho de capítulo quando comparados com o tratamento sem adição de fósforo.

A massa de 100 aquênios foi afetada pelos tratamentos, sendo que o MAP e MAP+SHS aplicados $100 \%$ a lanço proporcionaram menor acúmulo de massa nos aquênios comparativamente com as outras formas de parcelamento do adubo fosfatado. Quando os adubos foram aplicados todo no sulco de semeadura o MAP proporcionou maior massa de aquênios. Todos os adubos aplicados $100 \%$ a lanço e o organomineral aplicado $67 \%$ a lanço não diferiram do tratamento sem adição de fósforo, e os demais resultaram em maior massa de aquênios comparativamente ao tratamento sem fósforo.

Para a produtividade o adubo organomineral aplicado $67 \mathrm{e}$ $100 \%$ a lanço não diferiram do tratamento sem adição de fósforo, os demais tratamentos proporcionaram produtividade de aquênios maior que esse tratamento. Havendo ainda variações na resposta dentro das fontes em razão da forma de aplicação.

\section{DISCUSSÃO}

A menor altura e massa seca de planta podem indicar deficiência nutricional, apesar de apenas o tratamento sem adição de P no Latossolo Vermelho-Amarelo ter ficado com teor foliar abaixo de $2,90 \mathrm{mg} \mathrm{kg}^{-1}$, valor considerado critico por Castro e Oliveira (2005). A altura é um componente importante em cultivos mecanizados, sendo que ela deve ser uniforme para proporcionar colheita eficiente com menores perdas (PIVETTA et al., 2012). O maior diâmetro da haste, proporcionado pela maior disponibilidade de nutrientes dissolvidos no solo, resulta em maior sustentação da planta e reduz o risco de quebra ou acamamento, consequentemente perda na colheita (SANTOS et al., 2015).

Deve-se ressaltar a diferença entre os dois solos, principalmente, quanto ao acúmulo de massa seca de plantas, onde se observou menor efeito do adubo organomineral no Latossolo Vermelho em comparação com o Latossolo Vermelho-Amarelo. Isso ocorre devido aos teores de matéria orgânica de cada solo, sendo que o primeiro solo apresenta maiores valores em relação ao segundo. Santos et al. (2013) em solo com 12, $87 \mathrm{~g} \mathrm{~kg}^{-1}$ de matéria orgânica encontraram resposta do girassol adição de adubo organomineral até a dose de 3.650 $\mathrm{kg} \mathrm{ha} \mathrm{a}^{-1}$.

Com o aumento da dose a lanço há a redução do nutriente próximo as raízes, e uma maior interação do nutriente presente no adubo com as partículas sólidas do solo, fato que é diminuído quando toda dose é fornecida no sulco de semeadura, onde as fontes com substâncias húmicas proporcionaram maior massa seca que o MAP (exclusivamente mineral). Um fato que deve ser levado em conta é que as substâncias húmicas atuam no crescimento de raízes e absorção de nutrientes pelas plantas (ATIYEH et al., 2002; CANELLAS et al., 2002) o que pode ter contribuído para maior acúmulo de massa seca do girassol. Amoacy (2006) indica que há viabilidade da adubação fosfatada em superfície quando o teor de P no solo for alto e as condições físicas e climáticas forem ideais e mesmo nessas condições pode ocorrer problemas devido à baixa mobilidade do elemento no solo.

Os valores de $\mathrm{P}$ no solo na instalação dos experimentos de 17,7 e 4,5 $\mathrm{mg} \mathrm{dm}^{-3}$ para o Latossolo Vermelho-Amarelo (178 g $\mathrm{kg}^{-1}$ de argila) e Latossolo Vermelho (588 $\mathrm{g} \mathrm{kg}^{-1}$ de argila), respectivamente, foram limitantes para o girassol proporcionar o máximo crescimento e produtividade de aquênios necessitando de adubação fosfatada evidenciado pela resposta apresentada.

Nesse estudo, tanto no solo com disponibilidade adequada (Latossolo Vermelho-Amarelo) como no solo com baixa disponibilidade de P (Latossolo Vermelho), a adubação fosfatada feita totalmente a lanço reduziu o crescimento e produtividade de aquênios do girassol. Esse efeito se agrava pelo período de cultivo, tornar essa cultura mais suscetível a deficiência hídrica, principalmente no estágio de enchimento de aquênio. Por isso, a concentração de nutriente na superfície do solo, especificamente o P considerado de baixa mobilidade no solo, pode influenciar o crescimento radicular da cultura impedindo o seu desenvolvimento em maior profundidade do perfil do solo (Valadão et al., 2015) com consequente redução da absorção de nutrientes e produtividade.

Para o Latossolo Vermelho-Amarelo o adubo MAP (fonte exclusiva mineral) pode ser aplicado $100 \%$ a lanço sem redução de produtividade e as fontes contendo substâncias húmicas proporcionam aumento de produtividade de aquênio quando comparada ao MAP, porém tem que ser aplicada no mínimo $33 \%$ da dose no sulco de semeadura. Para o Latossolo Vermelho que possui textura mais argilosa, tanto o MAP quanto o adubo organomineral tem que ser aplicada no mínimo $67 \%$ da dose de $80 \mathrm{~kg} \mathrm{ha}^{-1}$ no sulco de semeadura, porém, para MAP+SHS apenas 33\% são necessários ser aplicado no sulco de semeadura. Isso indica que para esse solo, para a adubação ser adotada 100\% a lanço doses maiores que $80 \mathrm{~kg} \mathrm{ha}^{-1}$ de $\mathrm{P}_{2} \mathrm{O}_{5}$ teriam que ser aplicadas para não haver redução de produtividade o que implicaria no aumento de custo de produção. 
Em Latossolo Vermelho argiloso com disponibilidade de P adequada, Teixeira et al. (2013) encontraram que a aplicação do P 100\% a lanço proporcionou maior produtividade da soja comparado as formas parceladas a lanço e no sulco de semeadura, bem como ao sistema $100 \%$ no sulco de semeadura. Deve-se ressaltar que os autores utilizaram a dose de $100 \mathrm{~kg}$ ha ${ }^{1}$ de $\mathrm{P}$, dose superior a utilizada neste trabalho $\left(80 \mathrm{~kg} \mathrm{ha}^{-1}\right)$. Para Sousa; Lobato (2004), a aplicação de doses maiores que $100 \mathrm{~kg}$ $\mathrm{ha}^{-1}$ podem ser aplicadas a lanço, no caso de doses inferiores para culturas anuais, recomenda-se sua aplicação em sulcos de semeadura, o que possibilita melhor uso do $\mathrm{P}$ do fertilizante solúvel em água.

Sachs et al. (2006), em Latossolo Roxo com 12,6 $\mathrm{mg} \mathrm{kg}^{-1}$ de P verificaram produtividades do girassol entre 1.387 e $1.738 \mathrm{~kg} \mathrm{ha}^{-1}$ sendo que a dose de $46 \mathrm{~kg} \mathrm{ha}^{-1}$ de $\mathrm{P}$ proporcionou a máxima produtividade de aquênios. Nesse trabalho se utilizou a dose de 80 $\mathrm{kg} \mathrm{ha}^{-1}$ nos dois solos e as produtividades ficaram entre $1.420 \mathrm{e} 2.676$ $\mathrm{kg} \mathrm{ha}^{-1}$ para o Latossolo Vermelho-Amarelo e entre 1.997 e $3.294 \mathrm{~kg}$ ha ${ }^{-1}$ para o Latossolo Vermelho. As produtividades encontradas neste trabalho são maiores que àquelas encontradas por outros autores e pela média de Mato Grosso que é de $1.669 \mathrm{~kg} \mathrm{ha}^{-1}$ (CONAB, 2019).

As substâncias húmicas por sua vez contribuíram para maior crescimento e produtividade de aquênios no Latossolo Vermelho-Amarelo. Souza et al. (2014) em estudo de sorção de P no solo na presença de ácidos orgânicos encontraram maiores efeitos em Latossolo mais argiloso. Contrariamente ao obtido pelos autores, neste trabalho o maior efeito das substâncias húmicas foi observado no solo mais arenoso. Um resultado semelhante foi observado por Dania et al. (2012), em solo degradado sob erosão superficial, onde as maiores produtividades de milho com a adubação organomineral quando comparado com a fonte exclusiva mineral.

O efeito das substâncias húmicas sobre o crescimento do girassol e produtividade de aquênios pode estar relacionado a maior disponibilidade de P (ANDRADE et al., 2003) e/ou a bioatividade sobre o crescimento radicular e absorção de nutrientes (ROSA et al., 2009). Rosa et al. (2009) verificaram aumento em até $30 \%$ na produção de massa da parte aérea de feijão na adição de substancias húmicas, e observaram que a massa seca da raiz aumentou linearmente até a maior dose de substâncias húmicas testada, sendo $41 \%$ maior que no tratamento sem substâncias húmicas. Esses resultados podem estar relacionados com o efeito auxínico sobre as plantas e com a ativação da $\mathrm{H}^{+}$ATPase de membrana plasmática. A ativação da $\mathrm{H}+$-ATPase promove aumento do gradiente eletroquímico de $\mathrm{H}^{+}$, provocando a acidificação do apoplasma que leva ao rompimento de ligações da parede celular, promovendo sua elasticidade, o que favorece o crescimento celular (CANELLAS et al., 2002). Assim o manejo que adiciona de forma continuada ácidos orgânicos, seria almejado, principalmente em solos mais intemperizados e pobres em matéria orgânica.

\section{CONCLUSÕES}

Produtos à base de substâncias húmicas contribuem para o crescimento e produtividade de aquênios do girassol, sendo mais eficientes em solos arenosos e pobres em matéria orgânica.

Para Latossolo Vermelho-Amarelo de textura média, o adubo MAP (monoamônio fosfatado) pode ser aplicado 100\% a lanço sem redução de produtividade. Nesse solo, fontes contendo substâncias húmicas tem que ser aplicadas no mínimo 33\% da dose no sulco de semeadura.

Para Latossolo Vermelho, textura argilosa, tanto o MAP (monoamônio fosfatafo) quanto o adubo organomineral tem que ser aplicado no mínimo $67 \%$ da dose no sulco de semeadura. Quando for acrescido substâncias húmicas ao MAP, apenas 33\% são necessários ser aplicado no sulco de semeadura.

\section{AGRADECIMENTOS}

Ao Instituto Federal de Mato Grosso (IFMT) e a Fundação de Amparo à Pesquisa de Mato Grosso (FAPEMAT) pelo apoio financeiro e concessão de bolsa de iniciação científica.

\section{REFERÊNCIAS}

AMOACY, F. C. Adubação na superfície ou incorporada? Plantio Direto, Piracicaba, v. 1, n. 73, p. 35, 2006.

ANDRADE, F. V.; MENDONÇA, E. S.; ALVAREZ, V. H.; NOVAIS, R. F. Adição de ácidos orgânicos e húmicos em Latossolos e adsorção de fosfato. Revista Brasileira de Ciência do Solo, Viçosa, v. 27, n. 6, p. 1003-1011, 2003. DOI: https://doi.org/10.1590/S0100-06832003000600004

ATIYEH, R. M.; LEE, S.; EDWARDS, C. A.; ARANCON, N. Q.; METZGER, J. D. The influence of humic acids derived from earthworm-processed organic wastes on plant growth. Bioresource Technology, New York, v. 84, p. 7-14, 2002. DOI: https://doi.org/10.1016/S0960-8524(02)00017-2

CANELLAS, L. P.; OLIVARES, F. L.; OKOROKOVAFAÇANHA, A. L.; FAÇANHA, A. R. Humic Acids isolated from earthworm compost enhance root elongation, lateral root emergence, and plasma membrane H-ATPase activity in maize roots. Plant Physiology, v. 130, p. 1951-1957, 2002. DOI: https://doi.org/10.1104/pp.007088

CASTRO, C.; OLIVEIRA, F. A. Nutrição e adubação do girassol. In: LEITE, R. M. V. B. C.; BRIGHENTI, A. M.; CASTRO, C. (Eds.) Girassol no Brasil. Londrina, EMBRAPA Soja. 2005. p.317-374.

CONAB_Companhia Nacional de Abastecimento. Acompanhamento de safra brasileira: grãos, $12^{\circ}$ Levantamento - Safra 2018/19. Companhia Nacional de Abastecimento. Brasília: Conab, 2019.

DANIA, S. O.; FAGBOLA, O.; ISITEKHALE, H. H. E. Effects of sawdust and organomineral fertilizer and their residual effect on the yield of maize on degraded soil. Pakistan Journal of Agricultural Sciences, Faisalabad, v. 49, n. 1, p. 61-66, 2012.

ELTZ, F. L. F.; VILLALBA, E.; LOVATO, T. Adubação fosfatada para girassol sob sistema plantio direto no Paraguai. Bragantia, Campinas, v. 69, n. 4, p. 899-904, 2010. DOI: https://doi.org/10.1590/S0006-87052010000400016

EMBRAPA_Empresa Brasileira de Pesquisa Agropecuária. Sistema brasileiro de classificação de solos. $5^{\mathrm{a}} \mathrm{ed}$. Rio de Janeiro, Embrapa, 2018, 356p.

EMBRAPA_Empresa Brasileira de Pesquisa Agropecuária. Manual de análises químicas de solos, plantas e fertilizantes. $2^{\circ}$ ed. Brasilia, Embrapa, 2009. 627p.

FONTANA, A.; PEREIRA, M. F.; SALTON, J. C.; LOSS, A.; CUNHA, T. J. F. Fósforo remanescente e correlação com as substâncias húmicas em um Latossolo Vermelho sob diferentes sucessões de cultura em plantio direto. Revista Brasileira de Agrociência, Pelotas, v. 14, p. 161-166, 2008. DOI: http://dx.doi.org/10.18539/cast.v14i1.1900

LANA, M. C.; RAMPIM, L.; VARGAS, G. Adubação fosfatada no milho com fertilizante organomineral em Latossolo Vermelho Eutroférrico. Global Science and Technology, Rio Verde, v. 7, n. 1, p. 26-36, 2014. DOI: https://doi.org/10.14688/19843801/gst.v7n1p26-36 
PAVINATO, O. S.; ROSOLEM, C. A. Disponibilidade de nutrientes no solo: decomposição e liberação de compostos orgânicos de resíduos vegetais. Revista Brasileira de Ciência do Solo, Viçosa, v. 32, n. 3, p. 911-920, 2008. DOI: https://doi.org/10.1590/S0100-06832008000300001

PIVETTA, L. G.; GUIMARÃES, V. F.; FIOREZE, S. L.; PIVETTA, L. A.; CASTOLDI, G. Avaliação de híbridos de girassol e relação entre parâmetros produtivos e qualitativos. Revista Ciência Agronômica, Fortaleza, v. 43, n. 3, p. 561 568, 2012

RODRIGUES, T. R. D.; BROETTO, L.; OLIVEIRA, P. S. R.; RUBIO, F. Desenvolvimento da cultura do milho submetida a fertilizantes orgânicos e minerais. Bioscience Journal, Uberlândia, v. 28, n. 4, p. 509-514, 2012.

ROSA, C. M.; CASTILHOS, R. M. V.; VAHL, L. C.; CASTILHOS, D. D.; SPINELLI, L. F.; OLIVEIRA, E. S.; LEAL, O.A. Efeito de substâncias húmicas na cinética de absorção de potássio, crescimento de plantas e concentração de nutrientes em Phaseolus vulgaris L. Revista Brasileira de Ciência do Solo, Viçosa, v. 33, n. 4, p. 959-967, 2009. DOI: https://doi.org/10.1590/S0100-06832009000400020.

SACHS, L. G.; PORTUGAL, A. P.; PRUDENCIO-FERREIRA, S. H.; IDA, E. I.; SACHS, P. J. D. Efeito de NPK na produtividade e componentes químicos do girassol. Semina: Ciências Agrárias, Londrina, v. 27, n. 4, p. 533-546, 2006. DOI: http://dx.doi.org/10.5433/1679-0359.2006v27n4p533

SANTOS,L. G.; SOUZA, U. O.; CARVALHO,Z. S.; PRIMO, D. C.; SANTOS, A. R. Análise de crescimento do girassol em função do suprimento de fósforo e boro. Bioscience Journal, Uberlândia, v. 31, n. 2, p. 370-381, 2015. DOI: https://doi.org/10.14393/BJ-v31n2a2015-22316

SANTOS, J. F.; WANDERLEY, J. A. C.; SOUSA JÚNIOR, J. R. Produção de girassol submetido à adubação organomineral. Agropecuária Científica no SemiÁrido, Patos, v. 9, n. 3, p. 38-44, 2013. DOI: http://dx.doi.org/10.30969/acsa.v9i3.387

SANTOS, L. G.; SOUZA, U. O.; PRIMO, D. C.; SILVA, P. C. C.; SANTOS, A. R. Estado nutricional da cultura do girassol submetido à adubação com fósforo e boro. Enciclopédia Biosfera, Goiânia, v. 6, n. 11, p. 1-15, 2010.

SANTOS, R. D.; GATIBONI, L. C.; KAMINSKI, J. Fatores que afetam a disponibilidade de fósforo e o manejo da adubação fosfatada em solos sob plantio direto. Ciência Rural, Santa Maria, v. 38, n. 2, p. 576-586, 2008. DOI: https://doi.org/10.1590/S0103-84782008000200049.

SOUSA, D. M. G.; LOBATO, E. Cerrado: correção do solo e adubação. $2^{a}$ ed. Brasilia, Embrapa Informação Tecnológica, 2004. $416 \mathrm{p}$

SOUZA, M. F.; SOARES, B. E. M.; SILVA, I. R.; NOVAIS, R. F.; SILVA, M. F. O. Competitive sorption and desorption of phosphate and citrate in clayey and sandy loam soils. Revista Brasileira de Ciência do Solo, Viçosa, v. 38, n. 4, p. 1153 1161, 2014. DOI: https://doi.org/10.1590/S010006832014000400011

TEIXEIRA, R. B.; ROQUE, C. G.; LEAL, A. J. F.; MINOTTO, V. A.; FREITAS, U. C. Formas de aplicação da adubação fosfatada na cultura da soja em semeadura direta. Revista de Ciências Agro-Ambientais, Alta Floresta, v. 11, n. 1, p. 9-15., 2013.
VALADÃO, F. C. A; WEBER, O. L. S.; VALADÃO JÚNIOR, D. D.; SCAPINELLI, A.; DEINA, F. R.; BIANCHINI, A. Adubação fosfatada e compactação do solo: sistema radicular da soja e do milho e atributos físicos do solo. Revista Brasileira de Ciência do Solo, Viçosa, v. 39, n. 1, p. 243-255, 2015. DOI: https://doi.org/10.1590/01000683rbcs20150144.

VIANELLO, R. L.; ALVES, A. R. Meteorologia básica e aplicações. $1^{\text {a }}$ ed. Viçosa, UFV, 2004. 449p.

ZABIOLE, L. H. S; CASTRO, C.; OLIVEIRA, F. A.; OLIVEIRA JÚNIOR, A. Marcha de absorção de macronutrientes pela cultura do girassol. Revista Brasileira de Ciência do Solo, Viçosa, v. 34, n. 2, p. 425-433, 2010. DOI: https://doi.org/10.1590/S0100-06832010000200016 